\title{
Función sociocultural de los albergues escolares en la mirada del Instituto Nacional Indigenista
}

\section{Sociocultural Role of School Shelters in the Eyes of the National Indigenist Institute}

\author{
Aleksandra Jablonska Zaborowska \\ Universidad Pedagógica Nacional, Ciudad de México, México \\ https://orcid.org/oooo-ooor-8759-8479 \\ aleksandra.jablonska@gmail.com \\ ISSN-OI85-4259; e-ISSN: 2007-9176 \\ http://dx.doi.org/I0.28928/ri/91202I/atc3/jablonskaa
}

\begin{abstract}
Resumen
El objetivo del artículo es analizar críticamente el discurso acerca del papel sociocultural que han jugado los albergues escolares creados por el Instituto Nacional Indigenista (INI), a partir de los materiales que forman parte del Acervo de Cine y Video Alfonso Muñoz del Instituto Nacional de los Pueblos Indígenas (INPI), incluyendo algunas producciones del Archivo Etnográfico Audiovisual (AEA). Al tratarse de una práctica social contextualizada, el discurso del INI acerca de la salud, la alimentación y la educación de la niñez indígena también estuvo sometido a modificaciones por los cambios en las políticas sociales de los sucesivos gobiernos mexicanos. Los primeros planteamientos asimilacionistas y asistencialistas con el tiempo dieron lugar a la incorporación formal del multiculturalismo, en sintonía con el proyecto de la democracia neoliberal. El análisis busca situar los discursos de INI en el entramado de la lucha política por la representación de la educación indígena en los últimos treinta años.

Palabras clave: discurso cinematográfico, políticas estatales, indigenismo, educación indígena, infancia.
\end{abstract}

\begin{abstract}
The objective of the essay is to critically analyze the discourse about the sociocultural role that the school shelters created by the National Indigenist Institute (INI) have played, based on the materials that are part of the Film and Video Collection Alfonso Muñoz, at the National Institute for Indingenous Peoples, including some produced by the Ethnographic Audiovisual Archive. Discourse is a contextualized social practice, therefore, changes in social policies of successive Mexican governments have also modified INI's discourse on health, nutrition and education of indigenous children. The early assimilationist and assistentialist discourses, over time gave rise to the formal incorporation of multiculturalism, in tune with the project of neoliberal democracy. The analysis seeks to situate INI's discourses within the framework of the political struggle for the representation of indigenous education in the last thirty years.
\end{abstract}

Keywords: Film speech, state policies, indigenism, indigenous education, childhood.

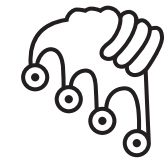

IZTAPALAPA

Agua sobre lajas 


\section{Introducción}

lobjetivo del presente ensayo es analizar críticamente los discursos fílmicos
acerca del papel sociocultural que han jugado los albergues escolares creados
por el Instituto Nacional Indigenista (INI) y luego por la Comisión Nacional para el Desarrollo de los Pueblos Indígenas (CDI). El examen se realiza, por un lado, a partir de una revisión de la narrativa cinematográfica y, por el otro, consultando los escritos de los antropólogos críticos que se han ocupado de los temas relativos al INI, sus proyectos educativos, de salud y alimentación, y su producción audiovisual.

El estudio del discurso cinematográfico incluye principalmente las imágenes (los planos, los encuadres, los movimientos de la cámara), el empleo de diversos tipos de voces, ${ }^{1}$ sonidos y música, y de la edición o montaje ${ }^{2}$ que le da el sentido final al discurso. Es frecuente que en los documentales, sobre todo los institucionales, el discurso verbal y el que es creado por las imágenes y la música se disocien. Eso ocurre, a mi juicio, en una de las películas analizadas, a saber, Días de Albergue (1990), de Alfonso Muñoz, que comentaré más adelante. Los demás filmes mencionados son típicos videos promocionales de la institución que busca crear en los espectadores la idea de que la población indígena se halla en un estado de extrema vulnerabilidad y que, aunque el INI y la CDI hagan esfuerzos enormes por resolver los problemas

1 Voz en over es una voz ajena al mundo de la diégesis que explica al espectador la problemática que aborda el filme de manera supuestamente objetiva y proyectando un alto grado de autoridad. La voz en off o acusmática es la de un personaje que participa en el filme pero que en este momento no aparece en la pantalla. La voz directa es la que pronuncia una persona a la que el espectador puede ver.

2 Si bien se trata de un procedimiento no exclusivamente cinematográfico, puesto que se ha usado en diversas artes, sin duda ha jugado un papel muy importante, puesto que implica cortes y posterior ensamblaje, que refleja siempre "una fase analítica en la cual el sujeto de enunciación desmiembra las unidades, los significantes con los que pretende expresarse y, por otra, una fase de organización, sintética o constructiva" (SánchezBiosca, 1996: 19). 
de pobreza, desnutrición infantil y falta de acceso a la escuela, sus recursos son insuficientes. Solo un filme, Generación futura (1995), de Alberto Becerril, hace una lectura crítica de la presencia del INI en la etnia mixe.

Parto de la idea de que el discurso es una práctica social contextualizada que tiene su origen en la vida social y que al mismo tiempo es un instrumento que crea vida social (Calsamiglia y Tusón, 200I: 15). Pero ello no ocurre al margen de las relaciones de poder que originan el dominio y la desigualdad social; por otro lado, son ejercicios de resistencia al orden hegemónico. Mi análisis, entonces, tiene como objetivo último situar los discursos del INI y la CDI dentro del entramado de la lucha política por la representación del tema de la educación indígena en los últimos 30 años.

Las películas y los videos que voy a analizar, además de las dos mencionadas, son: Programa Mundial de Alimentos en los Albergues Escolares (1988), Albergues Escolares Indígenas, compromiso para el mañana (2008) y Programa de Albergues Escolares Indigenas $(\mathrm{s} / \mathrm{f})$.

\section{El discurso del INI}

Hay una abundante bibliografía sobre el INI, por lo que solo recordaré los datos más importantes (Mutsuo y Gedgregori, 2002; Cusi, 2013; Lewis, 2018). Fue creado como una agencia del Estado en 1948 y su función ha sido la de incorporar a los niños indígenas a la sociedad nacional mediante el control cultural centralizado (Bonfil, 199I) y que ha ido incidiendo en una amplia gama de aspectos: organización de la vida cotidiana, enseñanza escolar, hábitos de alimentación y de higiene, así como las prácticas productivas.

Como ya han explicado diferentes autores, el principal objetivo del INI era coordinar todas las acciones estatales en las zonas de mayor densidad indígena (De la Peña, 2002: 5I). Se trataba de planear y ejecutar acciones muy diversas: las investigaciones antropológicas y sociológicas, el reparto de la tierra, los programas productivos, la atención a la salud y a la educación, de manera prioritaria. Las instituciones que se encargaban directamente de estas labores fueron llamadas Centros Coordinadores Indigenistas. Uno de sus objetivos era "aculturar" a los indios para que adquirieran una cultura y una identidad nacionales. Sin embargo, hubo resistencia tanto pasiva como activa por parte de las etnias a la política indigenista de la institución. En la década de 1970 se celebraron diversos congresos en los que se reclamaba un proyecto de revitalización cultural y autonomía política (De la Peña, 2002: 52). 
Aparentemente, la educación rural ha ocupado un lugar importante en el discurso estatal. En I99i la Secretaría de Educación Pública (SEP) inició el Programa para Abatir el Rezago Educativo (pare) en cuatro estados: Chiapas, Guerrero, Hidalgo y Oaxaca (Baas, Sánchez y Mena, 2000: 26). A partir de 1993 se extendió su cobertura a diez entidades con el llamado Programa para Abatir el Rezago de Educación Básica (pareb). En 1997 se inauguró el Programa Educación, Salud y Alimentación (PROGReSA) en 30 estados del país. Sin embargo, como señalan Baas, Sánchez y Mena,"muchos de estos apoyos eran ineficaces, o bien han sido utilizados con fines electorales" (2000: 26).

Los estudios acerca de la pobreza extrema que dominaba la vida de las comunidades rurales dispersas y los resultados de la evaluación realizada por la SEP en 1994 indicaron que la mayoría de las familias que vivían en condiciones de precariedad no tenían recursos para mandar a sus hijos a la escuela, con frecuencia muy alejada de su lugar de residencia. En este contexto, los albergues escolares se vieron como alternativas reales para mejorar las condiciones de higiene, de alimentación y acceso a la escuela primaria (Baas, Sánchez y Mena, 2000: 26).

\section{Un breve estado de conocimiento}

En México, durante los últimos 20 años se han realizado algunos estudios de caso sobre el papel de los albergues escolares creados por el INI en diversas regiones: Purépechas en Michoacán (Dietz, 1999), Mames en Chiapas (Hernández, 200I), Wixaritari (Durin, 2003), Mayas en Yucatán (Baas, Sánchez y Mena, 2000), por mencionar los más significativos.

Los autores coinciden en que en la gran mayoría de los casos las comunidades rechazan las acciones educativas desarrolladas por los Consejos Coordinadores Indígenas porque se trata de programas desarrollados por la burocracia que reside en la Ciudad de México, sin conocimiento de las culturas ni de las condiciones climáticas y productivas locales. Se trata, desde luego, de programas impuestos, no consensados con las etnias.

Otro problema señalado por los autores es que la institución indigenista suele arrogarse el derecho de determinar quién es indígena y quién no. Por ejemplo, se considera que son indígenas aquellos niños que hablan una lengua distinta al español, y que por esa razón pueden recibir una beca. El criterio lingüístico para caracterizar a los grupos étnicos es unánimemente rechazado por los antropólogos críticos. De acuerdo con estos, una etnia es sobre todo una forma de organización 
social, que tiene una base material y que al mismo tiempo comparte conocimientos, códigos simbólicos y emotivos (Bonfil, I99I: I7I-I72). Entre dichos códigos puede encontrarse la lengua, pero no es un elemento necesario ni aislado del resto de los aspectos mencionados.

La inadecuación de los planes y programas de estudios, la castellanización encubierta, el envío de maestros bilingües de otras regiones (por lo que no necesariamente hablan la lengua local), su intromisión en la vida de las comunidades, producen resistencia que se traduce en el ausentismo de los niños. Otro problema frecuentemente señalado es la inadecuación del calendario escolar al ciclo agrícola de cada región.

A su vez, la producción videográfica del INI fue abordada por varios autores. Conforme a Irma Ávila, a partir de 1977 la producción más importante de cine etnográfico se realizó gracias a la institución y su Archivo Etnográfico Audiovisual (AEA), que produjo cerca de roo películas basadas en la investigación antropológica (2014: 382). La autora reconoce, sin embargo, que se trataba de visiones de autor sobre las realidades indígenas, "realizadas con gran respeto por las comunidades y por sus protagonistas; sin embargo, no estaban dirigidas a las comunidades". Al final del día prevalecían los puntos de vista de los antropólogos y los cineastas (Ávila, 2014ः 32).

Alberto Becerril, quien trabajó en AEA entre 1984 y 1987 como investigador, realizador, posproductor y jefe del Archivo tiene una perspectiva aún más crítica. En la década de 1970, "La manera en que los miembros de las comunidades indígenas en que se había trabajado percibían la película realizada simple y sencillamente no era relevante ni para el cineasta, ni en general, para el antropólogo. Las películas 'sobre los pueblos indígenas en México' eran y siguen siendo en la mayoría de los casos, valoradas, evaluadas, clasificadas y premiadas por etnógrafos, antropólogos y cineastas" (Becerril, 2015: 32).

Para el autor esta actitud era un síntoma del colonialismo interno: se trataba de una cuestión ética, de respeto al otro, de normas mínimas de convivencia. No se podía usar la voz y la imagen del otro sin su consentimiento. El otro, sea indígena o no, debía participar en las decisiones sobre el contenido y el punto de vista de lo filmado. También debía involucrarse en la producción, edición y posproducción del filme (Becerril, 2015: 33-34).

Pero el estudio más completo ha sido realizado hasta este momento por Erica Cusi en el libro Indigenous media in Mexico (2013). Para dicha autora, estudiar los medios indígenas en México es necesariamente examinar las relaciones entre los indígenas y el Estado. Pero la historia de estas relaciones no es simple ni unidireccional. Quienes enseñaban a los pueblos originarios a usar los medios no eran burócratas, sino artistas y activistas comprometidos. A Cusi no le interesa estudiar 
las películas como textos, sino examinar la actividad social que tiene lugar en torno a la producción de los materiales videográficos, su circulación y consumo. En este sentido es posible entender que la cultura siempre está en formación, y que tanto los individuos como los grupos desempeñan un rol inventivo en sus propias culturas. Es por ello, y especialmente considerando la confrontación entre las culturas y el Estado, que la cultura es inherentemente política.

\section{Los albergues escolares en los videos del INI}

¿Como plantean esta problemática los videos producidos por el INI? Cronológicamente hablando, el primer filme sobre los albergues escolares alojado en el Acervo de Cine y Video Alfonso Muñoz ${ }^{3}$ es de 1988. Inciaba el sexenio de Salinas de Gortari. Se decidió aumentar el presupuesto para instituto y, en consecuencia, se expandió su infraestructura, incluyendo la creación del sistema de radios indígenas y unidades de producción fílmica situadas en las ciudades (Cusi, 2013: 38). Se produjo entonces la cinta Programa Mundial de Alimentos en los Albergues Escolares, dirigida por Heyerdal y realizada por el ini y el Programa Mundial de Alimentos.

El video dura i7 minutos y es un típico material promocional del in y de la Organización de las Naciones Unidas (oNU). Hecho con cierto descuido y narrado por una voz femenina en over que informa sobre el programa de la onu, el documental muestra mapas, gráficos y datos como si fuera un reportaje televisivo en el que aparecen imágenes para ilustrar lo narrado. Muchas de estas imágenes son de archivo, poco atractivas y sin un claro sentido (tiendas de Conasupo, mediante las cuales el pma distribuye los alimentos; camiones del Sistema de Distribuidoras de la Compañía Nacional de Subsistencia Populares (Diconsa-Conasupo), grupos de personas trabajando cargando sacos, o una imagen de niños africanos recibiendo un alimento).

Se nos informa que el IN libera parte de este presupuesto y lo destina a programas productivos. Los objetivos del instituto son los siguientes: "mejorar la dieta de los niños en los albergues escolares, realizar actividades agrícolas y pecuarias en los

3 Como afirma una nota del inpi, el Acervo de Cine y Video Alfonso Muñoz: "Cuenta con casi 3 mil cintas cinematográficas y 13 mil videos, distribuidos en seis fondos: Producciones videográficas terminadas INI-CDI, Producciones de cine transferidas a video terminadas INI-CDI, Producciones videográficas inconclusas, Producciones de Videoastas Indígenas, Congresos y Fondo de Producciones Externas". (http://www.cdi.gob. $\mathrm{mx} /$ acervos/acervo-cine-video.html). 
albergues que refuercen la educación escolarizada, desarrollar proyectos productivos en algunas comunidades indígenas, para propiciar la autosuficiencia alimentaria y propiciar la creación de fondos comunitarios que generen empleos".

También se afirma que los niños reciben una dieta balanceada que consta de "harina de maíz, frijol, arroz, pastas, aceite, sardinas, leche, huevos, carnes y verduras".

La tercera parte del video está dedicada a los proyectos productivos que apoya el Ini en diversos puntos del país. La voz over afirma que "el espíritu que anima los proyectos busca que las comunidades compartan la responsabilidad de su ejecución para erradicar las prácticas paternalistas que mucho les han afectado. Por ello una característica fundamental es que todos los proyectos deben ser autofinanciados, y es así que antes de la supuesta puesta en marcha se acuerda con la comunidad el porcentaje de la inversión que se canalizará al fondo comunitario."

La declaración final es casi triunfalista: "Con este enfoque integral, el INI apoya proyectos de naturaleza muy diversa: proyectos agrícolas, pecuarios, agroindustriales, de infraestructura, de pesca y artesanales. De esta manera se benefician con cada proyecto cerca de 250 padres de familia. Esto quiere decir que además de mejoramiento de la dieta alimenticia de los 64 mil niños albergados se verán beneficiadas 25 mil familias indígenas. Así es como con el apoyo del Programa Mundial de Alimentos (PMA), el INI logra una mejoría en las condiciones de vida de los pueblos indios de México".

En 1990, apenas dos años después, se filmó Días de albergue, por Alfonso Muñoz. ${ }^{4}$ El filme fue producido por la Subdirección de Imagen y Sonido del INI. La película dura 26 minutos y articula un discurso mucho más complejo que el anterior, por lo que voy a analizarlo e interpretarlo con más detenimiento.

El punto de vista de la narración reside desde un inicio en un agente externo a los pueblos indígenas, que no figuran sino como objetos de la atención del equipo fílmico. Desde sus inicios y hasta épocas recientes era muy común que el cine indigenista adoptara un punto de vista conforme al cual las etnias eran vistas como un otro, ajeno, lleno de carencias, y por lo tanto objeto de preocupación y estrategias diseñadas por las agencias estatales para "mejorar" su condición, sin que importara lo que los propios pueblos indígenas pensaran sobre ello, sin consultarlos y sin tomar en cuenta su organización social y política, sus formas de interacción y comunicación, sus conocimientos y pedagogías.

En efecto, desde los primeros segundos el video se introduce una voz en over femenina que afirma: "Los niños indígenas de México, integrantes de los sectores

4 El antropólogo Alfonso Muñoz Jiménez fue realizador de películas del INAH y del INI. 
más desfavorecidos y miserables del país, comparten con sus mayores no solo los territorios de difícil acceso y malas comunicaciones, sino también una cultura ancestral y condiciones de vida rayanas en la supervivencia".

Se trata de una visión que sigue prevaleciendo en nuestro país hasta hoy, pese a los cambios constitucionales que reconocen a los pueblos indígenas como sujetos de derecho y no de políticas asistencialistas. ${ }^{5}$ Inmediatamente la misma voz establece que uno de los problemas que enfrenta dicha población es la falta de acceso a la educación primaria.

Sin que medie algún tipo de problematización al respecto, como por ejemplo, por qué no se construyen las escuelas en las inmediaciones de sus hogares o si la educación primaria universal es la mejor alternativa para la educación de los niños indígenas, se plantea la solución: la existencia de los I 250 albergues operados por el INI. Eso indica que en dos años no se construyó ningún albergue nuevo. Pero el punto de vista sobre su papel es completamente distinto.

El discurso constantemente establece verdades que no permiten formular dudas: ¿cómo y con qué criterios se estableció la ubicación de los albergues?; ¿con qué requisitos deben cumplir los niños para acceder a ellos?; ‘es realmente una "solución" para los problemas que enfrenta la niñez indígena?

De pronto el discurso se interrumpe para mostrarnos directamente una mañana en un albergue. Lo que se subraya es la estricta disciplina a la que son sometidos los niños: "Son las seis de la mañana, ¡ todos a levantarse ¡Nuestra primera actividad es tender la cama!", exclama en tono decidido un hombre adulto y establece que dicha actividad debe cumplirse en Io minutos. Los niños, ya vestidos (¿durmieron

5 El artículo 2 de la Constitución, entre otras cosas, "reconoce y garantiza el derecho de los pueblos y las comunidades indígenas a la libre determinación y, en consecuencia, a la autonomía para: Decidir sus formas internas de convivencia y organización social, económica, política y cultural; Aplicar sus propios sistemas normativos en la regulación y solución de sus conflictos internos, sujetándose a los principios generales de esta Constitución, respetando las garantías individuales, los derechos humanos y, de manera relevante, la dignidad e integridad de las mujeres (...); Elegir de acuerdo con sus normas, procedimientos y prácticas tradicionales, a las autoridades o representantes para el ejercicio de sus formas propias de gobierno interno, garantizando que las mujeres y los hombres indígenas disfrutarán y ejercerán su derecho de votar y ser votados en condiciones de igualdad; así como a acceder y desempeñar los cargos públicos y de elección popular para los que hayan sido electos o designados, en un marco que respete el pacto federal, la soberanía de los Estados y la autonomía de la Ciudad de México. En ningún caso las prácticas comunitarias podrán limitar los derechos político-electorales de los y las ciudadanas en la elección de sus autoridades municipales". 
en pijama, pero los vistieron para que entraran las cámaras, o duermen en su ropa de día?) se apresuran para realizar la tarea. Por lo general, lo hacen entre dos (¿en cada camita duermen dos niños?). Después el adulto les recuerda quiénes forman los equipos para asear el dormitorio, el baño, quiénes deben ir al comedor y a la cocina.

Enseguida, el discurso en over se reanuda para decirnos otra "verdad": "Así es como 63000 niños $^{6}$ originarios de 44 de las 56 etnias que conforman nuestros mosaico cultural han dejado sus casas para convivir en estos hogares comunes. Aquí tienen la posibilidad de tener la educación primaria y enfrentar el futuro con más esperanza”.

De nuevo, ante una afirmación tan abstracta los espectadores tenemos dudas. ¿Esa cantidad de niños es grande, pequeña, suficiente? ¿Para los niños es fácil dejar sus casas para vivir en estos "hogares comunes"? ¿El tipo de educación que reciben les permitirá "enfrentar el futuro con más esperanza"?

La voz en over explica ahora que "El albergue escolar proporciona por 5 días de la semana y por todo el año lectivo, habitación y vivienda a 50 becarios...” Y nos preguntamos: ¿estos 50 becarios cómo se eligen? ¿Cuál es el universo total de los niños que aspiran a las becas? No lo sabremos si no buscamos datos en otras fuentes.

Inmediatamente el director del albergue habla del financiamiento que recibe la institución. Subraya que el presupuesto es insuficiente y que el mayor problema es el de la alimentación. Aunque reciben fondos federales del pma y apoyo de los padres de familia, muchos albergues "siguen sufriendo enormes carencias y la alimentación es de supervivencia". Quienes hemos visto el video anterior no podemos sino sorprendernos, ya que ahí se decía que los niños tenían una dieta balanceada que incluía carne, huevos, leche, frutas y mostrarnos charolas con tres divisiones en las manos de los niños. Solo una de las divisiones tiene verduras.

Mientras el director habla, la cámara se concentra en algo que parece ser frijoles. Las otras dos divisiones están vacías. Los niños comen tortillas. Nuestra angustia crece a medida que esta imagen se va multiplicando por decenas.

La voz en over afirma que la característica de estas escuelas es el bilingüismo porque los niños de los albergues hablan alguna de las " 56 lenguas que integran el universo lingüístico de México". Esta afirmación de nuevo nos deja dudas porque la misma voz nos acababa de informar que los niños del albergue van a las mismas escuelas que los niños mestizos que solo hablan en español. ¿Cómo se resuelve eso? ¿Se obliga a los niños mestizos a aprender todas las lenguas que hablan los otros niños? O bien, ¿se separa a los unos y a los otros?

6 Mil niños menos de lo que se decía en el video anterior. 
Aparecen después imágenes de una clase en que la docente muestra sucesivamente las imágenes de diferentes frutas, explica algo en alguna lengua y luego define en español: "manzana”," piña”. El "método" de enseñanza no parece muy exitoso. Los niños están distraídos, no interactúan con la maestra. Algunas niñas juegan con las tijeras, se las colocan en la boca. Mientras los maestros citadinos estamos alarmados al ver el peligro de la automutilación, la voz en over explica tranquilamente que todos los maestros son bilingües y que "deben ser además investigadores calificados, conocedores de la historia y la cultura de su etnia, y de la cultura nacional". ¿Es eso cierto?

La voz sigue elogiando a los maestros:"estos maestros indígenas empezaron sus carreras como promotores culturales alfabetizando a los adultos en sus comunidades. Por vocación escogieron ser educadores y cursaron sus carreras en escuelas normales especializándose en la educación bilingüe." Después del elogio, la voz nos regresa a la tierra diciendo: "el número de estos maestros es aún insuficiente ante la gran demanda de la población infantil, por lo que muchos de ellos tienen que atender simultáneamente a varios niveles en un mismo salón. El número de aulas a su vez no cubre las necesidades por el creciente número de alumnos y en muchos casos son improvisadas". Y como si eso fuera poco, agrega: "A pesar de los esfuerzos realizados hasta ahora, el rendimiento de estos estudiantes es bajo. Además de la pobre alimentación, casi generalizada, los niños tienen que ausentarse periódicamente de la escuela para realizar tareas agrícolas que les demandan los padres en la época de siembra y cosecha. De esta forma su educación primaria se ve prolongada hasta por varios años."

Lo que se nos muestra son, en efecto, aulas improvisadas, hechas de palos. Los niños hojean los libros. Nunca se nos dice qué tipo de formación se les transmite, por lo que intuimos que se trata de programas nacionales estandarizados para todo el país y que no distinguen entre las diversas culturas ni dan cuenta del "mosaico lingüístico". La "pobre alimentación" de la que tanto se habla en el video parece ser una condición fija, es decir, inalterable de la realidad. En cambio, la culpa de que los niños se ausenten de la escuela en épocas de siembra y cosecha es claramente de los padres de familia y no del calendario escolar que perfectamente podría adaptarse a la condición de la región en que se opera.

El video repite las secuencias en que se ve a los niños de diversos albergues lavar los platos. En cambio la información sobre otras maneras de formar a los niños proviene de la voz over, que hacia el final del video afirma que "otras actividades tienen como fin reforzar su identidad y enseñar al niño la cultura de sus mayores. Las formas usadas para la transmisión de este conocimiento son muy variadas, consistiendo en expresiones corporales, dramatizaciones, bailes y cantos". Solo podemos 
presenciar dos de estas dramatizaciones que se refieren a la medicina tradicional. En ambos casos son los maestros los que les recuerdan a los niños las palabras que deben decir.

Es también esta voz la que da el mensaje final: "Con aciertos y desaciertos el INI con su programa de albergues ha avanzado hacia la construcción de un mejor futuro para la niñez indígena de México con el apoyo del programa nacional de Solidaridad. ${ }^{7}$ Los pueblos indios quieren ser protagonistas de su desarrollo y eso solo se logrará cuando exista una estrecha colaboración interinstitucional y de respeto a las modalidades culturales de los pueblos indios y de reconocimiento a sus prácticas y conocimientos tradicionales."

No es difícil concluir que lo que se dice en el filme refleja exclusivamente el punto de vista institucional. Es el InI el que está a cargo del discurso hablado. Es significativo que los únicos entrevistados son los y las directoras de los albergues. No se les da la palabra a los otros actores que participan en el proceso: los maestros, los niños, los padres de familia. Mientras este discurso subraya las carencias de los albergues, sobre todo las alimenticias, trata de construir también una visión optimista sobre la función del INi en las regiones más marginadas del país.

El otro discurso, el que nos transmiten las imágenes es, creo, mucho más dramático. Las imágenes de los platos semivacíos que reciben los niños son estrujantes y se repiten con mucha frecuencia. La cámara muestra también los métodos pedagógicos que parecen remitir a la repetición de palabras y oraciones que pronuncian los maestros y al copiado de los libros. Las dramatizaciones están construidas por las o los maestros quienes en todo momento ayudan con los "diálogos". Los niños no se desempeñan en forma autónoma. Las canciones que se les enseñan no tienen que ver con su particularidad cultural, sino con el desarrollo de los hábitos higiénicos, o se trata de canciones que aprenden todos los niños mexicanos en primaria.

Sabemos que una película no puede proporcionar toda la información que un espectador exigente le demandaría. A diferencias de textos escritos, que pueden tener una extensión más o menos libre, al cine documental hasta hace poco se le pedía concisión. Pero el análisis del punto de vista del filme me llevó a comparar algunas de sus afirmaciones con el de las investigaciones antropológicas. Una de estas afirmaciones es que los maestros de las escuelas indígenas están muy bien preparados para trabajar en contextos multiculturales. Pero los investigadores niegan la existencia de carreras consolidadas en educación bilingüe en las normales mexi-

7 Se refiere al Pronasol (Programa Nacional de Solidaridad) que se creó durante el gobierno de Carlos Salinas de Gortari para atender a las poblaciones marginadas del país. 
canas. Irineo Rojas (1997) afirma que a los promotores culturales se les preparaba para castellanizar a los adultos y que se trataba de una preparación deficiente e improvisada destinada a los egresados de las primarias. Franco Gabriel ofrece datos sobre la educación indígena en el estado de Oaxaca. Después de la creación de la Dirección General de Educación Indígena en 1978,"los nuevos profesores, casi todos bachilleres, recibían solamente un curso de inducción a la docencia de dos a cuatro meses, que se incrementó a seis meses en 1990" (Gabriel, 20I0ः 274). La alternativa de formación la ofrecía la upN a través de la Licenciatura en Educación Indígena, solo obtuvo alrededor de $39 \%$ de profesores. ${ }^{8}$

Bruno Baronnet afirma que para el ciclo escolar 2009-2010 la nueva Licenciatura en Educación Intercultural Bilingüe se impartía apenas en 20 planteles educativos ubicados en I5 estados, lo que representaba menos de $2 \%$ de escuelas normales del país (Gabriel, 2010: 245-246). En realidad, la demanda de una educación bi e intercultural ha surgido siempre de los grupos de docentes disidentes, que han tenido que luchar contra el curriculum nacional uniforme impuesto una y otra vez por la SEP (2010: 246)

Gunther Dietz (1999) documentó el fracaso de la educación indígena en la región purhépecha por todas las razones que ya se han expuesto: falta de arraigo comunal de las escuelas federales, de los maestros, escasez de materiales didácticos en la lengua regional y métodos pedagógicos basados en la repetición y el copiado.

La siguiente película, de 60 minutos, titulada Generación futura ${ }^{9}$ y dirigida por Alberto Becerril Montekio , quien se basó en la investigación de Alberto Gonzalo Camacho, se realizó en 1995. A diferencia del material analizado anteriormente, este filme está centrado en el concepto de la etnia y su cultura, la mixe. Muchos de los elementos culturales se trasmiten mediante el trabajo de la cámara y de la banda sonora en que se reproducen piezas musicales ejecutadas por las bandas mixes y las canciones de un grupo de niñas. Se retrata la vida cotidiana, las formas de trabajo, los juegos de los niños, sus dibujos, el papel de los médicos tradicionales, las ceremonias en la montaña sagrada, pero también la intervención de los miembros de la Iglesia, de los médicos alópatas y de los maestros que trabajan en los albergues escolares.

En la zona hay dos albergues del ini, en San Pedro y San Pablo Ayutla y otro en Espíritu Santo Tamazulapam. El mayor problema es la pobreza y la desnutrición

El autor aporta datos conjuntos para los profesores con bachillerato y licenciatura.

La película fue galardonada con el premio al mejor documental de Ciencias Humanísticas en el Festival Internacional de Cine en Ronda, España en I996, y obtuvo el primer lugar en Antropología Visual. 
infantil, según la explicación de diversos actores sociales a los cuales se entrevista. En este filme podemos descansar de la voz en over, que buscaba imponer el punto de vista institucional.

Una de las directoras explica que dentro de poco, cuando inicie el ciclo escolar, van a llegar niños nuevos, a los que les va a costar mucho trabajo consumir la leche y otro tipo de alimentos. Llegan anémicos, no tienen ganas de trabajar, tienen sueño. Pero a diferencia de los albergues donde se alimenta a los niños, en escuelas pertenecientes a la educación indígena no hay ni desayunos ni material didáctico. La cámara muestra a los niños comiendo fritangas, una pasta sin ningún otro ingrediente, y su ropa agujereada. Un maestro pregunta a los niños de su clase que quiénes habían almorzado en su casa. Algunos no contestan. Otros dicen que comieron frijoles, otras más, tortillas, otros solo café.

Los médicos tradicionales, los alópatas y hasta una monja tratan de ayudar a resolver el problema. Sor Martha Garzafox tiene una casa cuna en Tlahuitoltepec donde recibe a niños severamente desnutridos. Algunos de ellos no logran levantarse de la cama durante seis u ocho meses, la que más ha durado acostada fue una niña que no logró pararse en tres años. Ahora empieza a moverse y gracias a las terapias, está empezando a hablar. Hay niños que no saben comer solos porque no logran mover las manos.

El doctor Bernal Torres, jefe del Departamento de Atención a la Salud del InI, explica que la desnutrición llega en Oaxaca a 60\% de los chicos que, cuando alcanzan la edad escolar traen desventajas en crecimiento y desarrollo. La zona mixe está en una situación más grave aún: "es eminentemente indígena, alejada de la ciudad, con pobreza, con una enorme cultura, pero sumamente aislada, incomunicada en algunas partes, lo que dificulta nutrientes adecuados". Otro problema es el cultural:

Desgraciadamente nuestros planes de estudio no están adecuados a las necesidades del país y menos para las regiones rurales y aún menos para las regiones indígenas. $Y$ lo que es peor, se da uno cuenta que lo que aprendió en la escuela no le sirve a uno mucho para curar a la gente o a prevenir las enfermedades y no únicamente desde el punto de vista médico sino desde el punto de vista sociomédico, de antropología médica. Trabajar en una región indígena implica trabajar con otra cultura diferente a la nuestra. Y si uno no entiende esa cultura, choca uno, ideológica, políticamente.

Una médica tradicional explica esa diferencia cultural: "muchos niños se enferman de diarrea, de vómito, de parásitos. A veces las diarreas no se quitan. Nosotros lo hidratamos, darle agua, suero casero. También le damos medicamentos, pero no se 
curan. Entonces son enfermedades tradicionales, mal de ojo, susto. Yo lo que les hago es la limpia y les digo qué ritos tienen que hacer, los hacen tres veces y se curan". Y el doctor Torres amplía el panorama:

En algunos casos los médicos tradicionales empiezan como topiles hasta poder ser presidentes o agentes municipales o topil de la Iglesia que sube hasta mayordomo y después toma el estatus de médico tradicional. Entonces es una persona con mucha calidad moral, y la gente le tiene fe, le tiene confianza, que no la tiene a nosotros. Estoy seguro que si no existiera la medicina tradicional, no existirían los actuales pueblos indígenas. Es una cultura propia de cada cultura indígena, que ha existido desde siempre, existe, a pesar del sector salud, a pesar de la conquista y ayudan a la población en cuestiones curativas, preventivas, cuestiones comunitarias. Se calcula que cerca del $80 \%$ de los nacidos vivos son atendidos por parteras y en regiones indígenas sube hasta el 96-97\%. Precisamente la región Mixe es una de estas regiones y en estos lugares con lo único que cuentan es con sus propios recursos terapéuticos. La gente hace más caso a ellos que a los médicos alópatas.

En el albergue del in en Espíritu Santo se enseña a los niños a cultivar las hortalizas. El director del albergue habla de problemas adicionales, niños desprotegidos, que no tienen quien los atienda, que no tienen madres o padres. El maestro habla con los niños sobre el machucado, pide que expliquen cómo se prepara y que lo dibujen. Es la comida ceremonial que se ingiere el primero de agosto con la idea de que así se evitará sufrir hambre "porque en este mes no hay cosecha, es el mes más difícil".

Uno de los rasgos culturales de la zona mixe que el filme muestra es la presencia tanto de la Iglesia católica como del culto a los dioses pertenecientes a la cosmovisión propia. La cinta inicia con el repiqueo de las campanas y segundos después vemos a dos hombres vestidos con camisas blancas que rezan en mixe:

Hoy venimos a la cima de la montaña a cumplir, a encontrarnos con el dador de la vida y del sustento. Nuestros antepasados, los Mixes, así lo determinaron, para ser protegidos del hambre y de la enfermedad. Que sean escuchadas nuestras palabras en la cima de la montaña, el trueno, el rayo y los diferentes vientos. Que nuestro rezo y nuestras palabras sean escuchadas. Hoy nos encontramos ofrendando a la naturaleza, pedimos ser guiados para poder reunirnos. Gracias juez. Gracias jefe.

Más adelante, Eloísa Flores Bravo afirma: 
Los médicos tradicionales atendemos a las personas que se enferman. Como decía antes, las personas se enferman de susto. Una persona que se asusta lejos, por ejemplo, en una ciudad, es difícil de que la persona se cure en su casa, entonces en estos casos vamos al cerro que en nuestro caso es Cempoatépetl, es el corazón de Dios, es donde sentimos que estamos más cerca de Dios, que es donde Dios nos escucha y estamos conscientes, o por lo menos yo los escucho y nuestra gente se cura.

Inmediatamente después vemos a las familias entrar en la iglesia con flores y veladoras, asisten a misa, reciben la comunión. Pero no se trata del sincretismo religioso. Entre la religión católica y la religiosidad mixe hay ciertas coincidencias. Por ejemplo, el concepto de la trinidad que es común a todas las religiones. Pero la concepción profunda y las prácticas mediante las cuales las poblaciones se relacionan con lo sagrado son diferentes. La convivencia con la naturaleza que se basa en una relación recíproca, el considerar a la Tierra como la madre, el papel fundamental del trabajo, y muchos elementos más permiten entender que se trata de vivencias muy diferentes a las que promueve la Iglesia católica.

Su pedagogía no se basa en los principios occidentales sino en la filosofía mixe, Wëjen Kajën que existe en la tradición oral y "para los comuneros significa despertar, desamarrar, desatar, aflorar las ideas y pensamientos, abrir los ojos a la inteligencia" (Delgado et al., 200I: 69). En primer lugar, la educación se concibe como un proceso y como una acción que tiene un fuerte vínculo con la cotidianidad, con la vida de la comunidad. Su sustento son los principios duales: Tierra-Vida, Trabajo-Tequio y Humano-Pueblo (Díaz Gómez, 2004ः 368; Obregón, 2010: 44, cit. en Jablonska, 2015: 237-238).

La yuxtaposición de las dos ceremonias, la católica y la ayuuk en la película puede llevar a una comprensión equívoca. Por eso es necesario recurrir a otras fuentes.

El alcance crítico del filme es mucho mayor que en los casos anteriores. Si bien se muestran las acciones del INI en el terreno de la salud, la alimentación y la educación, no hay una narración que pretenda convencernos de que la institución juega un papel central en las comunidades mixes. Por el contrario, escuchamos declaraciones de diversos actores sociales, algunos de ellos contratados por el propio INI, como lo es el doctor y el dentista, quienes tienen una visión crítica de las acciones gubernamentales puesto que están diseñadas para la población urbana y no comprenden las formas de vida de los pueblos indígenas. También queda claro que hay otros agentes que buscan soluciones a la problemática de las comunidades: una médica tradicional, una misionera, un maestro que pide a los niños que reflexionen y revaloren su cultura. 
El tema educativo prácticamente no es tocado, sino para decir que la educación indígena está abandonada. Las breves secuencias grabadas en los salones de clase no permiten comprender qué enfoques pedagógicos se emplean, si la educación es realmente bilingüe o bicultural.

\section{Los albergues escolares en los videos de la CDI}

La derogación del InI y la creación de la CDI se decidió durante el sexenio de Vicente Fox. Recordemos que durante su campaña en 1988 el futuro presidente prometió resolver el problema de Chiapas en solo 15 minutos. ${ }^{10}$ En el tercer año de su gobierno se realizaron algunas modificaciones jurídicas en que se planteó un nuevo modelo institucional de atención a la población indígena, la Comisión Nacional para el Desarrollo de los Pueblos Indígenas, y se promulgó la Ley General de Derechos Lingüísticos de los Pueblos Indígenas. Pero ¿cuál fue el contexto de este rediseño institucional? Haddlyyn Cuadriello (2008) identifica principalmente tres factores a los que el gobierno pretendió responder. En primer lugar, la crisis de la representatividad de las instancias tradicionales. Se trataba, entonces, de crear la impresión de que los pueblos indígenas iban a participar directamente en el diseño de las políticas, estrategias e instrumentos dirigidos a mejorar sus condiciones de vida, aunque en los hechos su participación en el Consejo Consultivo de la CDI estuviera subordinada a las decisiones del gobierno federal. Ello, argumenta la autora, se debió, entre otras cosas a que la población indígena se encuentra por debajo de la línea de pobreza con respecto a la media nacional y, por eso, "es muy probable que carezcan de las capacidades organizativas necesarias para poder participar de manera activa y propositiva en el diseño de las políticas públicas, por lo que difícilmente los más pobres podrán acceder a estos espacios públicos de deliberación para influir en las políticas e insertarse en esta nueva dinámica de relación con el Estado. Al respecto Joan Font (2004) señala que al traducirse las desigualdades sociales en desigualdades políticas, la participación ciudadana tiende a concentrarse en sectores muy reducidos y poco representativos". (Cuadriello, 2008: 12)

En segundo lugar, se trataba de formalizar la idea de que el gobierno instrumentaba las políticas del multiculturalismo, tal como ya se había asentado en el artículo segundo constitucional. Finalmente, se buscaba afianzar el proyecto de democracia

${ }^{10}$ Además prometió que cumpliría los acuerdos de San Andrés, que buscaría que se llevase a nivel constitucional la ley Cocopa, que reiniciaría el diálogo con los indígenas. 
neoliberal, que consistía en la transferencia de responsabilidades sociales del Estado hacia la sociedad civil y al sector privado (Cuadriello, 2008: 30).

Este nuevo contexto influyó poderosamente en el discurso de las películas producidas por la CDI. En Albergues Escolares Indígenas, compromiso para el mañana, producido en 2008 , se vuelve a emplear la voz en over y se utiliza el discurso ya muy gastado por la televisión mexicana en cuyo centro está "la gran familia". Así ahora se nos presentan los albergues como metáforas familiares en que todos - padres de familia, niños, cocineras, maestros y los jefes de los albergues- desempeñan un papel importante y contribuyen al éxito del proyecto. De acuerdo con este discurso, la nutrición es sana y balanceada, los aprendizajes son de alta calidad y hay bajo nivel de reprobación. Pero sobre todo se habla de afecto. Por ejemplo, la voz en over asegura que las comidas son aderezadas "con tres ingredientes básicos: afecto, dedicación y un gran espíritu maternal. Y así, los niños y las niñas se convierten en miembros de una gran familia en la que la diaria convivencia genera lazos de afecto y cariño, necesarios también para su desarrollo emocional".

Todas las personas entrevistadas en el video están encantadas: los niños dicen que en el albergue les gusta todo, y la voz en over agrega que esta experiencia significará "un parteaguas en su vida. Un antes y un después". Una de las cocineras dice que trabajar en el albergue fue el sueño de su vida, los y las profesoras del CoNAFE aseguran que están "muy a gusto".

A diferencia de los videos del INI, en que los padres de familia ayudaban sobre todo en la provisión de la comida, ahora se subraya mucho su colaboración prácticamente en todas las áreas: aseo de los baños, preparación de la comida, albañilería, limpieza de los jardines, etcétera.

La visión idealizante concluye con la siguiente afirmación: "Finalmente, en la gran familia del albergue no puede faltar el responsable del programa por parte de la CDI: él o ella se encarga de proveer, supervisar y contribuir a resolver los problemas que se van dando y la operación cotidiana del albergue, tarea que al igual que los otros miembros realiza con entusiasmo, dedicación, compromiso y sobre todo con un gran sentido de responsabilidad hacia los becarios".

El video regresa a una visión homogeneizadora del “indígena”, así que se filma lo mismo en Chiapas que en Jalisco y el Estado de México. Los nuevos elementos provienen del contexto político: se usa el lenguaje inclusivo y se alude al multiculturalismo para afirmar que lejos de ser un problema es una riqueza de las regiones. Se trata de dar la impresión de que los niños tienen el acceso a las tecnologías, de ahí que se repitan con frecuencia las imágenes de los alumnos sentados frente a las computadoras. Mis propias investigaciones (Jablonska, 2015) y los videos de Ojo 
de Agua Comunicación sobre las experiencias escolares exitosas ${ }^{11}$ indican que, aunque en algunas escuelas ubicadas en las zonas indígenas a veces hay algunas computadoras, estas la mayoría de las veces no están conectadas a internet. A su vez la CEPAL afirma:

La pertenencia a los pueblos originarios y a poblaciones de afrodescendientes es otro factor asociado a la brecha digital dentro de los países de América Latina y el Caribe. Se ha establecido que "la probabilidad de tener una computadora en el hogar es cinco veces mayor en el conjunto no indígena de la población que en los pueblos indígenas" (CEPAL, 2002, p.3I). Esto podría atribuirse a que la población indígena presenta niveles educacionales más bajos y habita en una mayor proporción en zonas rurales que las poblaciones no indígenas. Sin embargo, incluso en áreas urbanas, y con idénticos niveles educativos, los pueblos originarios siguen manifestando una menor probabilidad de acceso a las TIC (Villatoro y Silva, 2005: 12).

Pero hay otras transformaciones que documenta el video. En algunas regiones ya hay escuelas primarias cercanas a las que los niños pueden acudir. En estos casos los albergues hospedan a adolescentes en cuyas comunidades no hay secundarias ni preparatorias. En otras, de gran densidad de la población indígena, como la cora-huichol, faltan espacios y los niños viven hacinados. Esta revelación se aprovecha para hablar de problemas: la necesidad de reparaciones urgentes en varios albergues y la falta de agua. Y se encuentra la solución: "Por fortuna, desde algunos años se ha contado con el apoyo solidario y desinteresado de algunas fundaciones privadas". Nadie pronuncia el nombre de la fundación, pero en algunas puertas y ventanas de los albergues aparece el logo y el nombre de "Sabritas".

Una vez consultadas otras fuentes, resulta que la colaboración entre Sabritas y CDI se inauguró en 2004 y cuenta con propaganda que es divulgada por la prensa: "Fundación Sabritas cuenta con 29 albergues escolares indígenas que benefician a más de I 500 niños y jóvenes en todo el país"; "Desde hace ocho años, Fundación Sabritas impulsa el desarrollo de comunidades indígenas, mejorando la salud y educación de niños y niñas" ("Inaugura Fundación Sabritas...", 2009). A pesar de la

${ }^{11}$ Pueden verse en Ojo de Agua Comunicación en Vimeo (https://vimeo.com/ojodeaguacomunicacion). Entre estos videos se encuentran Tatutsi Maxakwaxi. Nuestro bisabuelo el venado de cola blanca (2009) de Roberto Olivares, Gozedzo dzedzo, aprendiendo lo nuestro (2009) de Juan José García, Jurhenkurbini Juchari Uandakurarbu Ueratini (2009) de Roberto Olivares, Asamblea escolar, nuestras palabras (2009) de Guillermo Monteforte. 
inauguración de nuevos albergues, su número absoluto ha disminuido puesto que el video reporta la existencia de I 070.

Otro video producido por el Programa de Albergues Escolares Indígenas y la Organización de Estados Iberoamericanos para la Educación, la Ciencia y la Cultura, sin fecha de producción, está filmado en varios albergues de Chiapas. Su discurso combina la información sobre la pobreza y la dispersión de las poblaciones indígenas, con las aseveraciones sobre las ventajas de poder vivir en un albergue escolar $y$, a su vez, sobre las dificultades que estos enfrentan para recibir a más niños y solventar los gastos. La constante del filme es que las personas que hablan a la cámara o mediante voz en off se presentan a sí mismas, explican brevemente sus funciones y hablan de los alcances y limitaciones que enfrentan. Hablan algunos niños y una chica que asegura que, gracias a lo aprendido en el albergue, ahora está estudiando la carrera de Lingüística y Cultura Maya en la Universidad de Oriente en Valladolid.

El video, que dura 7:24 minutos, termina con las solicitudes de apoyo a los inversionistas, las instituciones y a "gente que tiene dinero". Una niña dice que le gustaría tener cama para ella sola. Otro niño desea tener más espacio, más alimento y ser sano. El letrero final informa que:"Por cada niño atendido quedan cinco fuera del albergue, sin posibilidad de asistir a la escuela. Colabora con nosotros para que ninguno quede fuera."

Parece haber un retroceso en la forma de comunicar sobre las acciones del CDI, frente a lo que hacía el INI. Se recurre a metáforas desgastadas y al chantaje emocional para recaudar los fondos.

\section{Reflexiones finales}

"Conocer las miradas, o los modos de ver, es hoy esencial para entender la discriminación y la jerarquización”, dice Sarah Corona en la Introducción al libro Ver con los otros. Comunicación intercultural (2017) que escribió junto con Jesús Martín Barbero. Como he argumentado a lo largo del presente artículo, los discursos del INI (1988-2002) y de la CDI (2003-2008) están construidos con base en una de las corrientes del indigenismo aparentemente ya superada, la que veía a los pueblos originarios como atrasados, sumidos en la pobreza y en carencias culturales. De ahí que los filmes subrayen los esfuerzos de las agencias gubernamentales por alimentar y proporcionar la educación a los niños indígenas.

En efecto, con excepción de la Generación futura, todos los videos imponen el punto de vista oficial mientras excluyen la voz del otro y tampoco le permiten 
autorrepresentarse. A los niños indígenas y a sus familias se les retrata con la lástima que le debemos a los seres más débiles y carentes. Sus culturas, sus formas de pensar, sentir y actuar son invisibilizados. Se les niega la posibilidad de hablar: todas las veces que se expresa alguno de los protagonistas de los videos, se trata de un discurso controlado y previamente elaborado por quienes dirigen el filme. Las películas de Alberto Becerril y de Alfonso Muñoz representan más una apertura al cine autoral que los demás materiales analizados y que tienen un carácter estrictamente promocional e institucional.

La necesidad de controlarlo todo: las tomas, el montaje y a los personajes es reforzada por una voz en over o por los letreros que le dicen al espectador lo que debe comprender. Se excluye la posibilidad del análisis o la reflexión. Se dan cifras sobre el número de albergues y los niños atendidos que van variando de un video a otro, pero no se contextualizan, de modo que funcionan como abstracciones incomprensibles.

El InI y la CDI refuerzan los estereotipos construidos desde la mirada hegemónica. $\mathrm{Su}$ discurso va transformándose bajo la presión de la ideología neoliberal, que excusa de las responsabilidades sociales al Estado y las asigna a los particulares. En cambio, no se observa alguna influencia de la corriente intercultural y mucho menos de la perspectiva decolonial.

$\mathrm{Su}$ discurso está lleno de contradicciones: mientras en 1988 se asegura que las necesidades alimentarias de los niños están satisfechas, en los últimos filmes hechos por CDi se vuelve a poner acento en las carencias de los albergues escolares. Si los fundadores del INI calculaban que el instituto iba a resolver en 20 años "los problemas" que enfrentaban las comunidades originarias, tras más de 60 años de su existencia, no solo no se nota un avance en cuestiones tan básicas como la alimentación o la existencia de una infraestructura educativa suficiente (Lewis, 2018).

La postura del In f forzó la salida de varios de los videoastas que participaron en los talleres en que se enseñaba a los pueblos indígenas a hacer sus propios videos, $y$ luego en el Programa de Transferencia de Medios Audiovisuales a Comunidades y Organizaciones Indígenas. Algunos de ellos, como Guillermo Monteforte, uno de los fundadores de Ojo de Agua Comunicación, organización que se creó en 1996 y que funciona hasta hoy, elaboraron documentales "con un claro propósito político: apoyar la construcción de la autonomía de los pueblos, fortalecer su lucha por los derechos, avalar y conservar su propia cultura y producir información desde su propio punto de vista. (Jablonska, 2016: 228).

Alberto Becerril, a su vez, prefirió seguir su trabajo como investigador y realizador que, en lugar de facilitarse, se complicaba siguiendo en el INI. Colaboró con Guillermo Monteforte en talleres del proyecto de transferencia de medios e hizo 
documentales sobre la salud pública con financiamiento del Instituto Nacional para la Salud Pública. Recibió una beca de la Fundación Mac Arthur de tres años, gracias a la cual realizó cuatro documentales. Actualmente es docente, investigador y realizador en la Universidad Autónoma de Morelos (entrevista realizada en junio de 2020).

Sin duda, el programa del in de la transferencia de los medios a las comunidades indígenas rindió frutos a mediano plazo. Hoy personas y colectivos filman videos sobre la vida y los problemas que enfrentan las comunidades originarias en muchos lugares del país. Aunque el trabajo de algunos de ellos es ampliamente conocido y documentado, faltan más investigaciones actualizadas sobre el particular. La creciente presencia de los videos hechos por los propios indígenas o por quienes se identifican con ellos en plataformas digitales (wimeo, youtube) y en diversos festivales tiene un impacto político de mucha importancia. Los antes invisibilizados hoy tienen presencia y voz, mediante la producción videográfica, pero también a través de otras intervenciones artísticas, como lo son la fotografía, el muralismo y la pintura. ${ }^{12}$

Actualmente, al parecer, los albergues escolares están languideciendo. El Centro Estratégico en Justicia y Derecho para las Américas A.C. considera que los albergues están desapareciendo (2019). Informa que en Oaxaca hay 210 casas pero se canalizaron recursos solo para 49 de ellas; en Guerrero hay 99 albergues, pero solo se reporta un comedor. Donde se reciben recursos, se contemplan de 30 a 40 pesos para preparar tres comidas diarias. También la inseguridad está golpeando los albergues, porque muchas familias son desplazadas de sus lugares de origen.

En los tiempos de la pandemia de coronavirus, solo tenemos acceso a la propaganda oficial.

\section{Referencias bibliográficas y hemerográficas}

\section{Acervo de Cine y Video Alfonso Muñoz}

s./f. http://www.cdi.gob.mx/acervos/acervo-cine-video.html

12 En 2017 realicé un estado de conocimiento sobre las expresiones artísticas en los movimientos sociales, bajo el auspicio de la Red Mexicana de Estudios de los Movimientos Sociales. A partir de la lectura de 72 textos, entre libros, tesis y artículos, pude documentar una gran riqueza de las diversas expresiones, pero también la insuficiencia de las investigaciones sobre el particular. Dicho trabajo no se ha publicado aún. 
Ávila, Irma

2014 "México", en Alfonso Gumucio (coord.), El cine comunitario en América Latina y El Caribe, Bogotá, Fundación Frererich Ebert, Fundación del Nuevo Cine Latinoamericano, unesco, pp. 37I-430.

Baas, Mario, Pedro Sánchez y Francisco Mena

2000 "Papel de los albergues escolares en el desempeño escolar del niño en la zona rural de Yucatán”, Educación y Ciencia, 4(7), enero-junio 2000, pp. 23-35, http://educacionyciencia.org/index.php/educacionyciencia/ article/view/134

Baronnet, Bruno

2010 "De cara al curriculum nacional: las escuelas normales indígenas en las políticas de formación docente en México", en: S. Velasco y A. Jablonska, Construcción de politicas educativas interculturales en México: debates, tendencias, problemas, desafíos, Ciudad de México, México, Sep/upn, $\mathrm{pp}+245-272$.

Becerril, Alberto

2015 "El cine de los pueblos indígenas en el México de los ochenta", Revista Chilena de Antropología Visual, 25, julio, pp. 30-49, http://www.rchav. cl/img25/imprimir/2015_25_arto3_becerril.pdf

Bonfil, Guillermo

I99I "La teoría del control cultural en el estudio de procesos étnicos", Estudios sobre las Culturas Contemporáneas, Colima, México, IV(I2), pp. 165-204, https://www.redalyc.org/pdf/316/31641209.pdf

Calsamiglia, Helena y Amparo Tusón

200I Las cosas del decir, Barcelona, España: Ariel, https://universitas82.files. wordpress.com/2013/o8/las-cosas-del-decir.pdf

Cuadriello, Hadlyyn

2008 Neoindigenismo y participación ciudadana: El Consejo Consultivo de la CDI y la participación indígena, tesis de maestría, Facultad Latinoamericana de Ciencias Sociales, sede en México, https://www.researchgate.net/ publication/27785852I_Neoindigenismo_y_participacion_ciudadana_ el_Consejo_Consultivo_de_la_CDI_y_la_participacion_indigena

Cusi, Erica

2013 Indigenous Media en Mexico. Culture, community and the state, Durkham, Londres, Duke University Press. 


\section{De la Peña, Guillermo}

2002 "El futuro del indigenismo en México: del mito del mestizaje a la fragmentación neoliberal", en Estados nacionales, etnicidad y democracia en América Latina, Osaka, Japón, The Japan Center for Árera Studies/ National Museum of Ethnology.

Delgado, Manuel et al.

200 I "Bases filosóficas del proyecto educativo ayuujk y el proyecto pedagógico de El Bachillerato Integral Comunitario Ayuujk Polivalente BICAP", en $L a$ voz y la palabra del pueblo ayuujk, México, BicAP/ Miguel Ángel Porrúa/UpN.

Diario Oficial de la Federación

2003 Ley de la Comisión Nacional para el Desarrollo de los Pueblos Indígenas, 2I de mayo.

Díaz, Floriberto

2004 "Comunidad y comunalidad", en Diálogos en la acción, segunda etapa, pp. 365-374.

\section{Dietz, Günther}

1999 "Indigenismo y educación diferencial en México: balance de medio siglo de políticas educativas en la región purhépecha", Revista Interamericana de Educación de Adultos, file://C:/Users/88ir8/Downloads/art-Cre$\mathrm{fal} \% 2 \mathrm{O}(2) \cdot \mathrm{pdf}$

Durín, Séverine

2003 "Redefiniciones identitarias. Sacrificio de toro e intervención institucional entre los Wixaritari (Huicholes), Revista de Antropología Experimental, 3, https://revistaselectronicas.ujaen.es/index.php/rae/article/ view/2106, DoIः 10.1756I/rae

Gabriel, Franco

2010 "La construcción social del curriculum bilingüe e intercultural para la formación de docentes indígenas de educación primaria en Oaxaca", en: S. Velasco y A. Jablonska, Construcción de politicas educativas interculturales en México: debates, tendencias, problemas, desafíos, México, SEP/ UPN, pp. 273-316.

Hernández, Rosalba

200 I "La antropología aplicada al servicio del estado-nación: aculturación e indigenismo en la frontera sur de México", Journal of Latin American Anthropology, 6(2), pp. 20-4I. 
"Inaugura Fundación Sabritas albergue escolar indígena en Papantla, Veracruz" 2009 https://www.expoknews.com/inaugura-fundacion-sabritas-albergue/ Jablonska, Aleksandra

2015 "La Universidad Comunal Intercultural del Cempoaltépetl: un proyecto político, cultural y pedagógico”, en Patricia Medina, Pedagogías insumisas. Movimientos politico-pedagógicos y memorias colectivas de educaciones otras en América Latina, México Cesmeca/upn/Juan Pablos, pp. 235254.

Lewis, Stephen

2018 Retbinking Mexican Indigenismo, Albuquerque, University of New Mexico Press.

Martín- Barbero, Jesús y Sarah Corona 2017 Ver con los otros. Comunicación intercultural, Ciudad de México, FCE.

Muñoz Güemes, Alfonso

2018 "La construcción de la identidad étnica a través de la lente cinematográfica. Una ruptura narrativa en la era global", Saskab. Revista de discusiones filosóficas desde acá, cuaderno I2, http://www.ideaz-institute.com/sp/ CUADERnOi2/Ci22.pdf

Mutsuo, Yamada y Carlos Degregori

2002 Estados nacionales, etnicidad y democracia en América Latina, Osaka, The Japan Center for Area Studies.

Radiotele

s./f. "Lleva SEE apoyos alimenticios y didácticos a albergues escolares, rurales e indígenas", disponible en: http://www.radiotele.com.mx/ lleva-see-apoyos-alimenticios-y-didacticos-a-albergues-escolares-rurales-e-indigenas/.

Rojas, Irineo

1997 La educación bilingüe en México, Sinéctica, Io, enero-junio.

Villatoro, Pablo y Alisson Silva

2005 Estrategias, programas y experiencias de superación de la brecha digital $y$ universalización del acceso a las nuevas tecnologías de información y comunicación (TIC). Un panorama regional. CEPAL. 


\section{Filmografía}

Albergues escolares indígenas, compromiso para el mañana. Año de producción: 2008. Producción y dirección: Lourdes Hidalgo. Realización: Alejandro Romero. Camarógrafo: Héctos Tapia. Edición: Alejandro Romero, Lourdes Hidalgo, Edgar Romero. Posproducción: Julio Otriz. Musicalización: Alejandro Romero. Fotografía: Fernando Pimentel

Días de albergue. Año de producción: 1990. Realización: Alfonso Muñoz. Investigación y Producción: Subdirección de Imagen y Sonido. Fotografía: Hugo Vera. Sonido en campo: Rodrigo Rivas. Edición: Sybille Hayem. Producción ejecutiva: Alfonso Muñoz

Generación futura. Año de producción: 1995. Realización: Alberto Becerril Montequio. Investigación: Gonzalo Camacho, Alberto Becerril. Producción: Salvador Coronel. Fotografía: Carlos Cruz Barrera. Asistente de fotografía: Crisanto Manzano. Sonido en campo: Alejandro Camarena. Fotografía fija; Alberto Becerril. Guión: Alberto Becerril. Edición: Alberto Becerril, Guillermo Monteforte. Producción ejecutiva: Neyra Alvarado, César Ramírez, José Luis Sagredo, Alberto Becerril. Música: CECAM

Programa de Albergues Escolares Indigenas. Sin fecha de producción. Coproducción: CDI y OEI (Organización de Estados Iberoamericanos para la Educación, la Ciencia y la Cultura).

Programa Mundial de Alimentos en Albergues Escolares. Año de producción: 1988. Dirección: Ernesto Heyerdhal. Asistente de realización: Fabiola Ysunza Amigot. Camarógrafos y fotografía: Federico Chao Fuente y José Vicente Resina. Sonido: Genaro López Gutiérrez. Locución: Laura Luengas Díaz. Efectos especiales: Raúl Gómez Galindo. Material de archivo: Diconsa, onu. Coproducción: INI/ Programa Mundial de Alimentos. 
Aleksandra Jablonska Zaborowska

Aleksandra Jablonska Zaborowska es profesora- investigadora de la Universidad Pedagógica Nacional y del Posgrado en Historia del Arte de La Universidad Nacional Autónoma de México. Tiene doctorados en Historia del Arte y es miembro del Sistema Nacional de Investigadores, nivel I. Sus últimas publicaciones son: Jablonska, Aleksandra (202I), “Cómo representar lo ausente? El análisis de la Tempestad de Tatiana Huezo" en: Luciano, Mauro y Tatiana Guenaga (orgs), Análise filmica e sus resonancias. Entre imagens da bistoria, literatura y psicoanálise, pp. 97-II5, Brasil, Universidad Federal de Sergipe, ISBN978-65-86195-38-5; Jablonska, Aleksandra (2020), "Todo sobre mi madre en la autoconstrucción de lo femenino", en: A. Ortega y S. Anchondo, Otra mirada. Mujeres en séptimo arte, pp. 335-346, CDMx: Río Subterráneo, Humanidades, pp. 335-346, ISBN: 978- 607-8532-65-o y Jablonska, Aleksandra (2020), "Las películas de carretera latinoamericanas en la era de la globalización”, en: E. Cantón-Carrillo, E. Camacho Navarro, G. Nárvaez, (coord.), Trasnacionalidad, cine y audovisual en América Latina, CDMx, unAM, CIALC. ISBN 978-607-30-3508-8.

Citar como: Aleksandra Jablonska Zaborowska (2021),"Función sociocultural de los albergues escolares en la mirada del Instituto Nacional Indigenista", Iztapalapa. Revista de Ciencias Sociales y Humanidades, núm. 91, año 42, julio-diciembre de 2021, ISSN: 2007-9176; pp. 67-92. Disponible en <http:// revistaiztapalapa.izt.uam.mx/index.php/izt/issue/archive > . 